\title{
Evaluation of Thermocyclic Oxidation behavior of HVOF Sprayed WC-CrC-Ni Coatings
}

\author{
B. Somasundaram, Ravikiran Kadoli and M.R. Ramesh
}

\begin{abstract}
In the present study, the WC-CrC-Ni powder is HVOF sprayed on three different $\mathrm{Fe}$-based steels namely SA213-T22, MDN-310 and SUPERFER 800H. Oxidation studies have been conducted on the coated as well as uncoated specimens at $700^{\circ} \mathrm{C}$ for 50 cycles in air under cyclic heating and cooling conditions. The weight change method was used to establish the kinetics of oxidation. WC-CrC-Ni coated steels showed slow oxidation kinetics and considerably lower weight gains than that of uncoated steels. The superior performance of WC-CrC-Ni coatings can be attributed due to the formation of a compact and protective oxide layer consisting of $\mathrm{Cr}_{2} \mathrm{O}_{3}$, $\mathrm{NiO}$ and their spinels like $\mathrm{NiCr}_{2} \mathrm{O}_{4}$ and $\mathrm{NiWO}_{4}$. The uncoated T22 steel suffered a catastrophic degradation in the form of intense spalling of the scale. The combined technique of $X$-ray diffraction (XRD), scanning electron microscopy/energy dispersive $X$-ray analysis (SEM.EDAX) and X-ray mapping were used to analyze the oxidized products of coated and bare substrate steels.
\end{abstract}

Keywords--- Protective Coatings, WC-CrC-Ni, HVOF, High Temperature Oxidation

\section{INTRODUCTION}

$\mathrm{P}$ OWER plants are one of the major industries suffering from severe oxidation, corrosion and erosion problems resulting in the substantial losses [1]. Oxidation and Corrosion from the firing of coal or oil is essentially related to specific impurities in the fuels which can lead to the formation of non protective scales or can disrupt normally protective oxide scales. There are three general areas where external oxidation and corrosion problems occur in the water wall or boiler tubes near the firing zone, the high temperature superheater and reheater tubes and ductwork that handles the combustion flue gases [2].

In search for cost-effective solutions for E-C problems, various coatings like thermal sprayed coatings have become attractive. The term thermal spray describes a family of processes that use chemical or electrical energy to melt (or soften) and accelerate particles of a material which is then deposited on a surface[3]. The quality of the coatings obtained by thermal spray techniques is related to the nature of the

B. Somasundaram, Sr. Asst Professor, Mechanical Department, Reva Institute of Technology, Bangalore, India. E-mail:somasunder.b@gmail.com

Ravikiran Kadoli, Professor, Mechanical Department, National Institute of Technology Karnataka, Surathkal, India.E-mail:rkkadoli@rediffmail.com

M.R. Ramesh, Assistant Professor, Mechanical Department, National Institute of Technology Karnataka, Surathkal, India. E-mail:rameshmr@ nitk.edu.in

DOI: 10.9756/BIJIEMS.10413 process and the processing parameters. On the other hand, thermal spray coatings are a good option to repair components and prevent excessive wear because during the deposition process no significant changes to the microstructure of substrates or excessive deformation are promoted [4].

The latest technology that completes the current family of thermal spray techniques is the high velocity oxy fuel process. This thermal spray technology uses the kinetic energy and the output of a supersonic flow of burned gases, to soften and to propel the spray powder onto the substrate. The ability to deposit coatings from a wide range of metals, cermets, and ceramics leads to the application of HVOF spraying in many different industries[5-7]. It is common knowledge today that the HVOF systems are capable of processing better carbide coatings than other thermal spray methods in terms of higher hardness and bond strength, lower oxides and porosity, combined with low residual stress in the coatings. The high kinetic energy of the powder particles with shorter residence time result in the deposition of dense coatings during HVOF process. This process is highly promising due to the benefits of lower cost, better performance, ability to deposit coatings whose thickness ranges from several micrometers to tenths of a millimeter, ability to deposit on a wide variety of shapes and sizes [8-10].

The development and use of WC-based coatings with metallic binders is now generally acceptable practice in fossil fuel energy processes. These coatings are selected primarily for applications requiring enhanced wear resistance and surface hardness and to a lesser extent, their oxidation and corrosion resistance. Numerous studies have been conducted on binary WC-Co based coatings and ternary WC-Co-Cr coatings, and to a lesser extent on WC-Ni and WC-CrC-Ni coatings [11].

Lutz-Michael Berger et al. [12] reported that WC(W,Cr)2C-Ni coatings are having much superior oxidation and corrosion resistance to that of other commercial WCbased coatings and discussed that the composition WC(W,Cr)2C-Ni can bridge the gap between WC-Co and Cr3C2$\mathrm{NiCr}$ with regard to oxidation and corrosion resistance.

The objective of this work is to study the high temperature oxidation behaviour of HVOF sprayed WC-CrC-Ni coatings in air environment at an elevated temperature of $700^{\circ} \mathrm{C}$. This coating combines the high wear resistance of $\mathrm{WC}$ and $\mathrm{CrC}$ and high temperature oxidation resistance of $\mathrm{Cr}_{2} \mathrm{O}_{3}$. There is no reported literature on the oxidation behaviour of $\mathrm{HVOF}$ spray deposited WC-CrC-Ni coating on the selected boiler steel substrates. Therefore, the current work has been focused to study the influence of HVOF sprayed WC-CrC-Ni coating on the oxidation behaviour of the boiler steels. The 
thermocyclic conditions used in the present study represent a more realistic approach towards solving the problem of oxidation and corrosion in real time applications, where conditions are more or less cyclic rather than isothermal. Furthermore, the high temperature boiler studies could provide an idea concerning the adhesion between the coatings and the substrate steels under thermal heat shocks.

\section{EXPERIMENTAL PROCEDURE}

\section{A. Development of Coatings}

The Fe-based Super alloy designated as Superfer 800 (Midhani Grade), chrome moly steel designated as ASTMSA213-T22 and austenitic steel designated as MDN 310 (Midhani Grade) were used as substrate materials. The chemical composition of the substrate steels is reported in Table 1 . The specimens with close dimensions of $25 \mathrm{~mm} \times$ $25 \mathrm{~mm} \times 5 \mathrm{~mm}$ were prepared for oxidation studies, ground with $\mathrm{SiC}$ papers down to 180 grit and were grit-blasted with $\mathrm{Al}_{2} \mathrm{O}_{3}$ powders previous to HVOF spraying for developing enhanced adhesion of the coating to the substrate.

HVOF spraying has been done using a HIPOJET 2700 equipment (M/S Metallizing Equipment Co.Pvt.Ltd, Jodhpur, India), which make use of the supersonic jet generated by the combustion of liquid petroleum gas and oxygen mixture. A commercially available (WC - 20CrC - 7Ni) powder of nominal composition [W - $19 \mathrm{Cr}-7.25 \mathrm{Ni}-6.8 \mathrm{C}$ ] (wt \%), was used as feedstock alloy. As evident from the micrographs of the coating powders shown in Fig.1a, the WC-CrC-Ni powder particles have spherical morphology. The particle size distribution of the powder as determined by the image analysis of the secondary electron micrographs are found to be in the range of $15 \mu \mathrm{m}$ to $45 \mu \mathrm{m}$, consistent with the nominal size distribution as provided by the manufacturer. XRD peaks of the powder reveal that powder has crystalline phases of WC, $\mathrm{Cr}_{7} \mathrm{C}_{3}$ and $\mathrm{Cr}_{3} \mathrm{Ni}_{2}$, where as in the coatings, WC decompose to brittle $\mathrm{W}_{2} \mathrm{C}$.(Fig $1 \mathrm{~b}$ ). All the process parameters, including the spray distance, were kept constant throughout the coating process and they are given in Table 2. The optical image along the cross-section of as-sprayed coatings were obtained by using Zeiss Axiovert inverted optical microscope, interfaced with image analyzing software to find out the porosity content. Twenty fields of view per sample were taken at 250X magnification.

Table 1: Chemical Composition (Wt \%) of Boiler Tube Steels

\begin{tabular}{|c|c|c|c|c|c|c|c|c|c|}
\hline Type of steel & $\mathrm{Fe}$ & $\mathrm{Ni}$ & $\mathrm{Cr}$ & $\mathrm{Ti}$ & $\mathrm{Al}$ & $\mathrm{Mo}$ & $\mathrm{Mn}$ & $\mathrm{Si}$ & $\mathrm{C}$ \\
\hline SA213-T22 & Bal. & - & 2.5 & - & - & 1.1 & 0.5 & 0.4 & 0.1 \\
\hline MDN 310 & Bal. & 21 & 25 & - & - & - & 2.0 & 0.8 & 0.1 \\
\hline Superfer 800 & Bal. & 32 & 21 & 0.3 & 0.3 & - & 1.5 & 1.0 & 0.1 \\
\hline
\end{tabular}

The uncoated and HVOF coated steels were subjected to thermocyclic oxidation tests at $700^{\circ} \mathrm{C}$ in silicon carbide tube furnace for 50 cycles. The furnace was calibrated to an accuracy of $\pm 5^{\circ} \mathrm{C}$ using Platinum/Platinum-13\% Rhodium thermocouple fitted with a temperature indicator. Physical dimensions of the specimens were then measured with the help of vernier caliper to evaluate their surface areas. Afterwards, the specimens were washed properly with acetone and dried in an oven to remove any moisture. The boat containing the specimen was introduced into hot zone of the furnace set at a temperature of $700^{\circ} \mathrm{C}$. Holding time in the furnace was one hour in still air after which the boat with the specimen was taken out and cooled at the ambient temperature for 20 minutes. Following this, weight of the boat along with specimen was measured with the help of a Electronic Balance Model AY-120 with a sensitivity of 1mg and this constitutes one cycle of oxidation study. Any spalled scale in the boat was also taken into consideration for the weight change measurements. Visual observations were made after the end of each cycle with respect to color, luster or any other physical aspect of the oxide scales being formed. The samples after being subjected to oxidation were analysed using SEM/EDAX and XRD techniques. The reproducibility in the experiments was established by repeating the experiments for some samples.

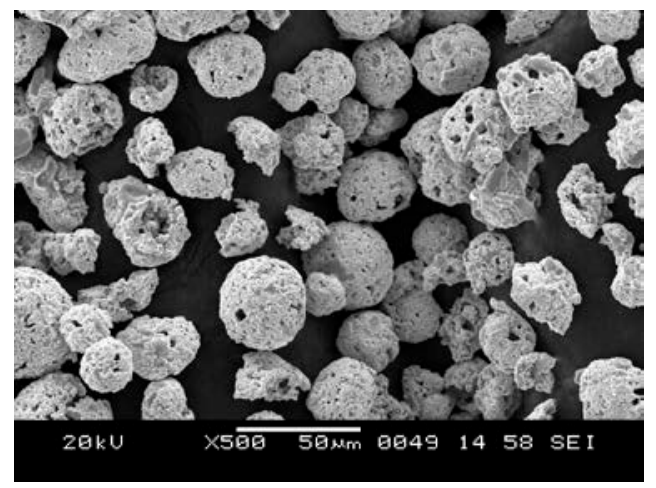

(a)

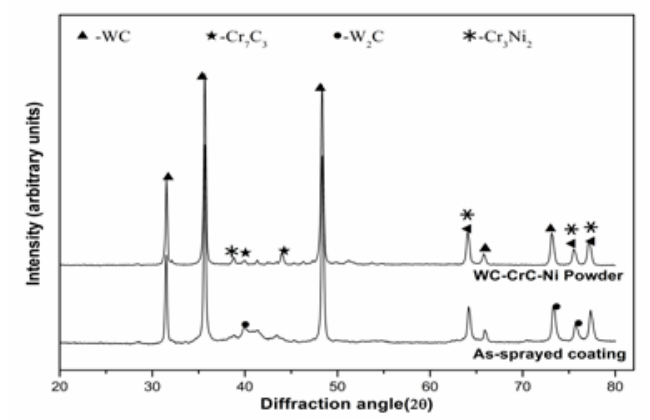

(b)

Figure 1: (a) Scanning Electron Micrograph of WC-CrC-Ni Powder; (b) X-ray Diffraction Patterns for Powder and asSprayed Coating

\section{B. High Temperature Oxidation Test}


Table 2: Spray Parameters Employed for HVOF Spray Process

\begin{tabular}{|l|l|}
\hline Oxygen flow rate & $250 \mathrm{l} / \mathrm{min}$ \\
\hline Fuel (LPG) flow rate & $65-70 \mathrm{l} / \mathrm{min}$ \\
\hline Air-flow rate & $550 \mathrm{l} / \mathrm{min}$ \\
\hline Spray distance & $178 \mathrm{~mm}$ \\
\hline Powder feed rate & $23 \mathrm{~g} / \mathrm{min}$ \\
\hline Fuel pressure & $681 \mathrm{kPa}$ \\
\hline Oxygen pressure & $981 \mathrm{kPa}$ \\
\hline Air pressure & $588 \mathrm{kPa}$ \\
\hline
\end{tabular}

\section{RESULTS}

\section{A. Coating Structure and Properties}

The HVOF coatings have been deposited on a stationary substrate and the necessary thickness has been achieved by varying the required number of passes. The thickness of the coatings has been found to be in the range of $270-300 \mu \mathrm{m}$. The average porosity value of the coatings was found to be less than $2.5 \%$. The average microhardness value found to be 1093 Hv with a standard deviation of 76 . The bond strength of the coating was measured as $73.13 \mathrm{MPa}$ whereas the HTK Ultra Bond epoxy glue used in the present study had a characteristic tensile strength of $80 \mathrm{~N} / \mathrm{mm}^{2}$. This indicates that the coating cohesive strength is superior to the adhesive strength.

The optical crossectional micrograph of the coating before oxidation is illustrated in Fig.2, which shows the deposition and build up of melted particles in a layered fashion and then solidifies in the form of fine spalt during impact. The micrograph mainly consists of $\mathrm{Cr}_{3} \mathrm{C}_{2}$ or Ni phase and WC phases. The dark spots distributed in the optical image are the porosity and porosity are mainly produced at grain boundary between $\mathrm{Cr}_{3} \mathrm{C}_{2}$ and WC phase or between Ni and WC phase. Contrast dark areas close to coating substrate interface are inclusions.

\section{B. Thermogravimetric Studies}

The macrographs of the uncoated and HVOF sprayed coated steels subjected to cyclic oxidation in air for 50 cycles are shown in Fig. 3. All the uncoated alloys developed a dark grey coloured oxide scale. During the cyclic oxidation, the minimum spallation of scale was observed for the Mdn steel as compared to the other steels. The scale formed on the T22 steel was found to be fragile and cracked from centre of the sample. The color of the oxide scale on the surface of all the three coated steels is greenish grey. The oxide scale was found to be compact and strongly adherent to the substrate, with no tendency for spalling.

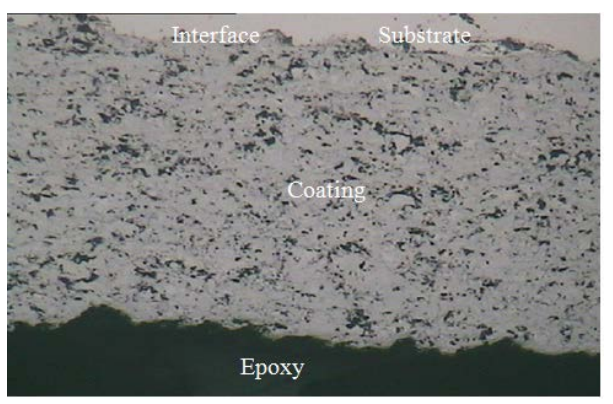

Figure 2: Optical Micrographs Showing Cross-sectional Microstructures of as-sprayed Coatings
The macrographs of the uncoated and HVOF sprayed coated steels subjected to cyclic oxidation in air for 50 cycles are shown in Fig. 3. All the uncoated alloys developed a dark grey coloured oxide scale. During the cyclic oxidation, the minimum spallation of scale was observed for the Mdn steel as compared to the other steels. The scale formed on the T22 steel was found to be fragile and cracked from centre of the sample. The color of the oxide scale on the surface of all the three coated steels is greenish grey. The oxide scale was found to be compact and strongly adherent to the substrate, with no tendency for spalling.
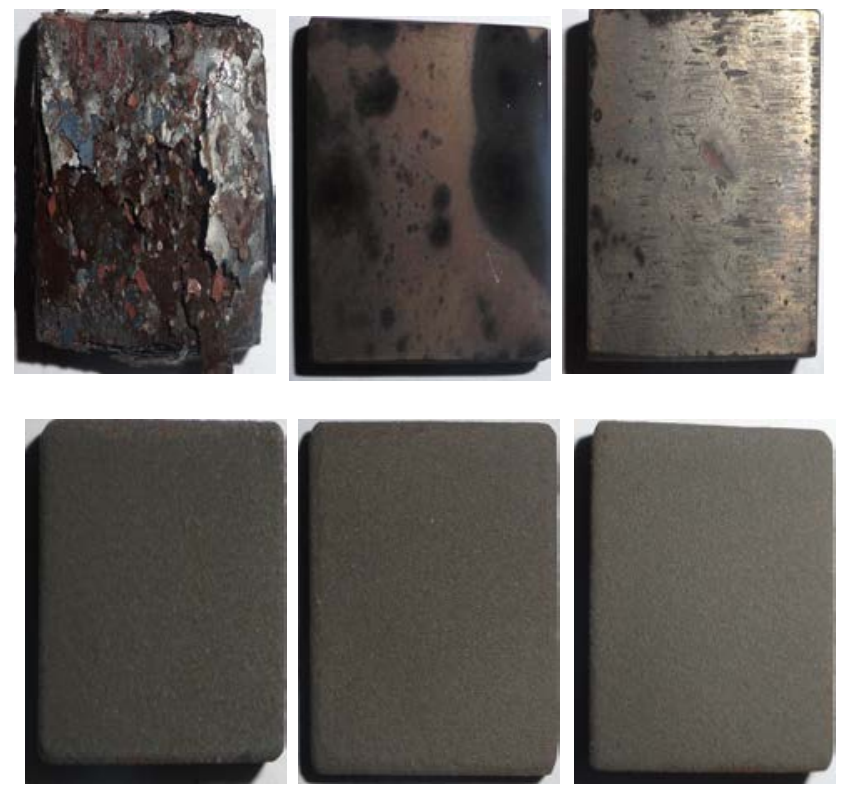

Figure 3: Macrographs of Uncoated Substrates (top row, in Sequence for T22, Mdn and Superfer-800H) and WC-CrC-Ni Coating (bottom row, in sequence for T22, Mdn and Superfer - 800H) Subjected to Oxidation in Air

The plots of cumulative weight gain $\left(\mathrm{mg} / \mathrm{cm}^{2}\right)$ as a function of time expressed in number of cycles are shown for uncoated and coated steels in Figs. 4(a) and 4(b). The weight gain for the T22, MDN and Superfer steels at the end of 50 cycles are found to be $16.89,0.67$ and $0.63 \mathrm{mg} / \mathrm{cm}^{2}$ respectively. Clearly, the T22 steel showed a maximum weight gain during the cyclic oxidation studies as compared to MDN and Superfer steels. The total weight gain values for the coated T22, MDN and superfer steels at the end of 50 cycles of oxidation studies are found to be $0.79,0.34$ and 0.50 $\mathrm{mg} / \mathrm{cm}^{2}$ respectively. The variation in weight change values is due to Sputtering of thin oxide layer formed on the surface of the coatings. Though a small difference exists in weight gain for different coated substrates, the net weight gain for all coated materials is less compared to weight gain for uncoated substrates.

Therefore it can be inferred from the thermogravimetric data that the required protection against cyclic oxidation has been provided by WC-CrC-Ni coatings. 

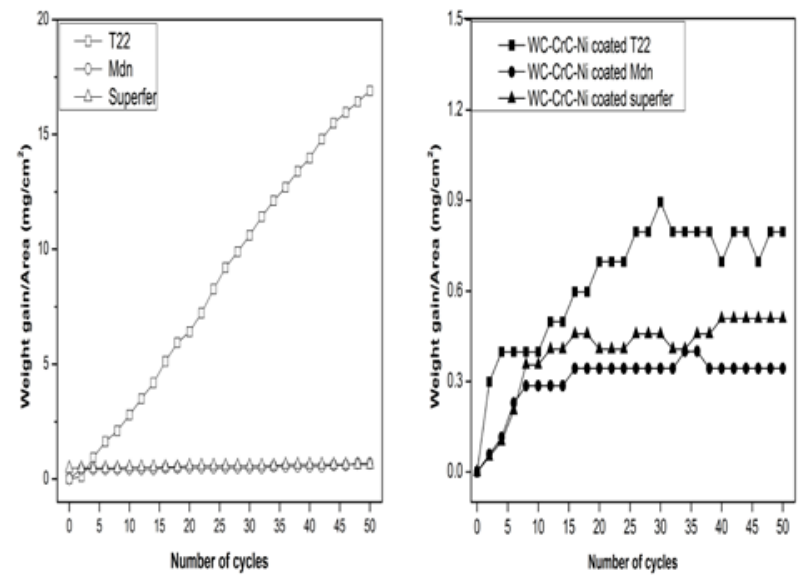

Figure 4: Plot of Weight Gain/area vs. Number of Cycles. (a) Uncoated Steels, (b) Coated Steels subjected to Oxidation for 50 cycles at $700^{\circ} \mathrm{C}$

The plot of weight gain square versus time (Fig. 5a) for uncoated steels shows the observable deviation from the parabolic rate law for T22 steel, which indicate that the oxide films were poorly protective at $700^{\circ} \mathrm{C}$. It is evident from the plot that the MDN and Superfer steels followed parabolic behaviour. The parabolic rate constant $\mathrm{K}_{\mathrm{p}}$ was calculated by a linear least-square algorithm function in the form of $(\Delta \mathrm{W} / \mathrm{A})^{2}$ $=\mathrm{K}_{\mathrm{p}} \times \mathrm{t}$, where $\Delta \mathrm{W} / \mathrm{A}$ is the weight gain per unit area, and $\mathrm{t}$ is the oxidation time in seconds. The $K_{p}$ for the T22, MDN and Superfer steels are $16.92 \times 10^{-10}, 0.0143 \times 10^{-10}, 0.000246 \times 10^{-10}$ $\mathrm{g}^{2} \mathrm{~cm}^{-4} \mathrm{~s}^{-1}$ respectively. All the coated steels show parabolic behaviour (Fig. $5 b$ ) and the $K_{p}$ for the coated T22, MDN and Superfer steels are found to be $3.4694 \times 10^{-12}, 5.6388 \times 10^{-13}$ and $1.2666 \times 10^{-12} \mathrm{~g}^{2} \mathrm{~cm}^{-4} \mathrm{~s}^{-1}$ respectively.
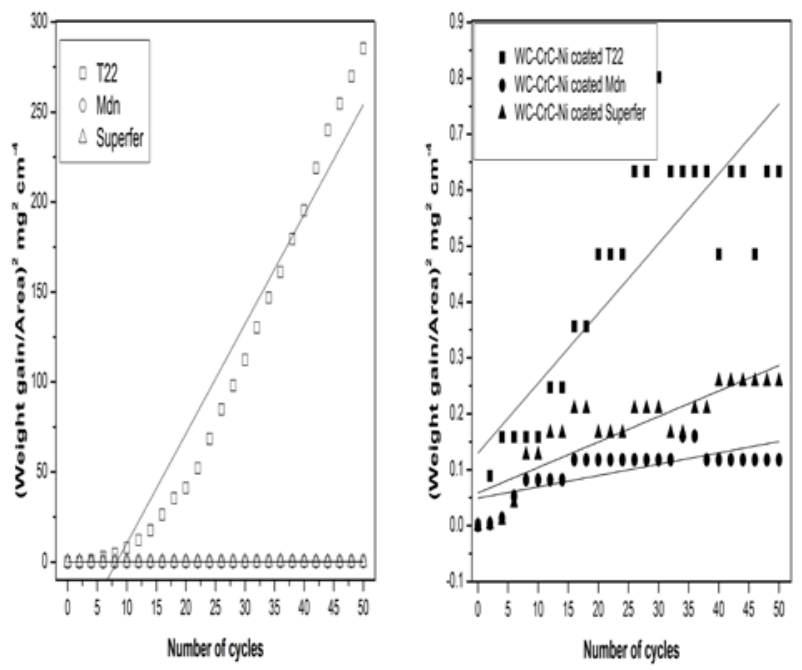

Figure 5: Plot of (Weight gain/area) ${ }^{2}$ vs. Number of Cycles. (a) Uncoated Steels, (b) Coated Steels subjected to Oxidation for 50 cycles at $700^{\circ} \mathrm{C}$

\section{X-ray Diffraction Analysis}

The X-ray Diffraction patterns of the oxide scale formed on the surface of oxidized WC-CrC-Ni coated steels after cyclic oxidation in air at $700^{\circ} \mathrm{C}$ are shown in Fig.6. The XRD results reveal the presence of the phases like $\mathrm{Cr}_{2} \mathrm{O}_{3}, \mathrm{NiO}, \mathrm{WO}_{3}$, WC and mixed spinal-type oxides of $\mathrm{NiWO}_{4}$, and $\mathrm{NiCr}_{2} \mathrm{O}_{4}$. The $\mathrm{Cr}_{3} \mathrm{C}_{2}$ phase in the as-sprayed coating has been transformed into $\mathrm{Cr}_{2} \mathrm{O}_{3}$ after oxidation. All the three coated steels have been found to have identical oxides on the surface.

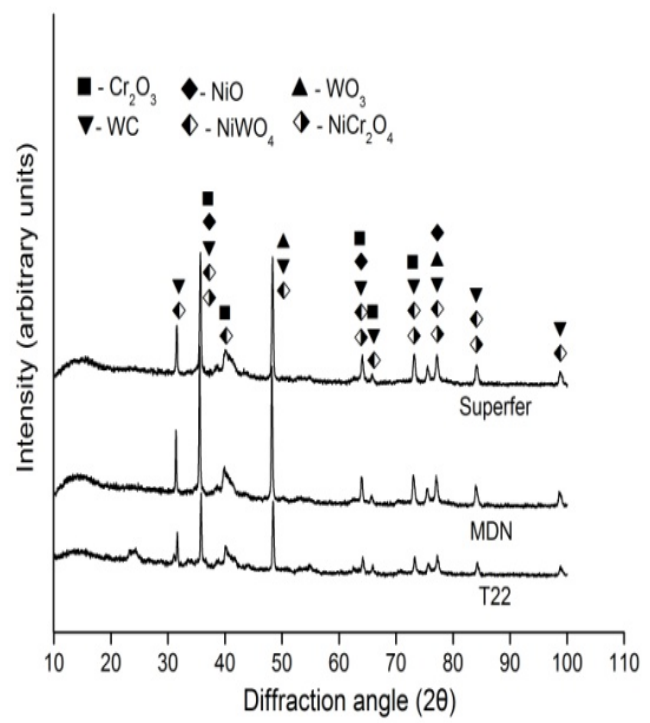

Figure 6: X-ray Diffraction patterns for Coated Steels Subjected to Cyclic Oxidation in Air

\section{SEM/EDAX Analysis}

The surface morphology (Fig. 7) of the oxide scale formed on the surface of WC-CrC-Ni coated steels is thick, continuous and non uniformly consisting of voids. Fig.7a shows the surface morphology of oxide scale formed on the oxidised WC-CrC-Ni coated T22 steel. Oxide scale consists of spherical globules dispersed in the non uniform matrix. The EDAX analysis on the spherical globules revealed the possibility of formation of oxides and carbides of tungsten and chromium $(35.73 \% \mathrm{~W}, 10.04 \% \mathrm{Cr}, 28.64 \% \mathrm{C}$ and $16.46 \% \mathrm{O})$ as the main constituent along with $\mathrm{NiO}(8.03 \% \mathrm{Ni})$ and the EDAX analysis on the matrix showed similar morphology composed of oxides and carbides of tungsten and chromium (37.44\%W, $17.08 \% \mathrm{Cr}, 21.57 \% \mathrm{C}$ and $19 \% \mathrm{O})$ as principal phases along with a minor amount of $\mathrm{NiO}(4.87 \% \mathrm{Ni})$. 

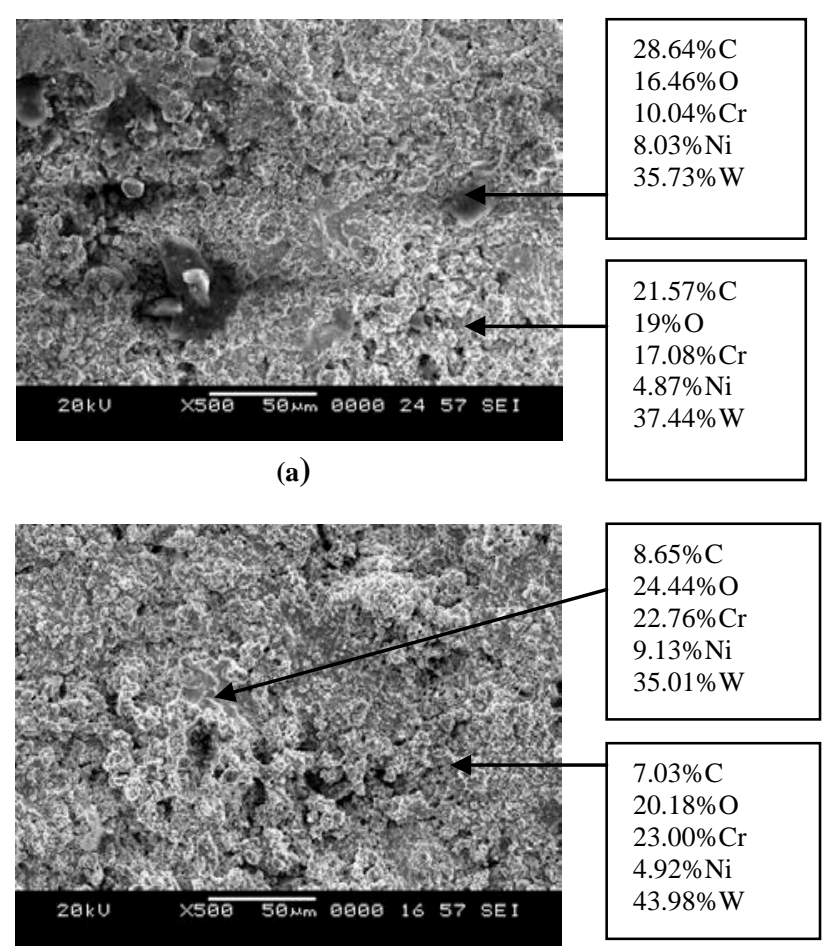

(b)

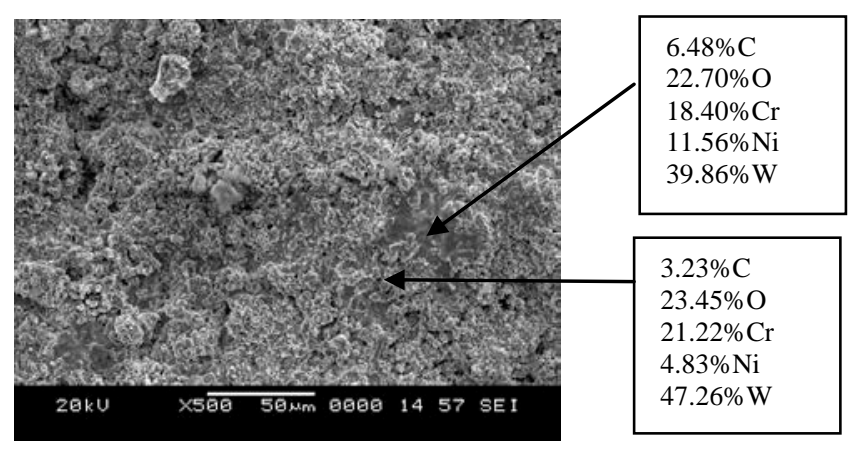

(c)

Figure 7: Surface Scale Morphology and EDAX Point Analysis for Coated Steels subjected to Oxidation: a T22 steel; b Mdn steel; c superfer steel

Similar observations have been noticed for the WC-CrCNi coated MDN and superfer steel (Fig. 7b and Fig. 7c). The dominating presence of $\mathrm{W}, \mathrm{Cr}$ and $\mathrm{Ni}$ peaks supports the possibility of formation of spinels of mixed oxide of $\mathrm{W}, \mathrm{Cr}$ and $\mathrm{Ni}$ on the surface of the oxidized coating.

\section{E. Cross-Sectional Analysis}

The BSE image and EDAX point analysis across the crosssection of the oxidized WC-CrC-Ni coated T22 steel at $700^{\circ} \mathrm{C}$ are shown in Fig. 8. A continuous, crack free and thick oxide scale is formed on the coated T22 steel which has retained the lamellar structure during the course of study. The topmost part of the scale (point 1), containing mainly $\mathrm{Cr}, \mathrm{W}$ and $\mathrm{Ni}(26.94$ $\mathrm{Wt} \%$ of $\mathrm{Cr}, 29 \mathrm{Wt} \%$ of $\mathrm{W}, 5.07 \mathrm{Wt} \%$ of $\mathrm{Ni}$ ) with about 21.04 $\mathrm{Wt} \%$ of $\mathrm{O}$ and $17.01 \mathrm{Wt} \% \mathrm{C}$ is rich in oxides and spinel oxides of $\mathrm{Cr}$ and $\mathrm{Ni}$ and carbides of $\mathrm{Cr}$ and W. EDAX analysis has detected $34.92 \mathrm{Wt} \%$ of $\mathrm{Cr}, 16.79 \mathrm{Wt} \%$ of $\mathrm{W}, 6.23$ $\mathrm{Wt} \%$ of $\mathrm{Ni}$ with $20.27 \mathrm{Wt} \%$ of $\mathrm{O}$ and $20.88 \mathrm{Wt} \%$ of $\mathrm{C}$ at point
2. Thus it can be inferred that the subscale (Point 2) is also rich in oxides and carbides similar to the topmost part of the scale. The light grey area (points 4 and 6) across the crosssection is detected as nickel rich splats $(44.66 \mathrm{Wt} \% \mathrm{Ni}$ at point 4 and $39.1 \mathrm{Wt} \% \mathrm{Ni}$ at point 6 respectively), mostly in an un-oxidised state, as relatively lesser amount of oxygen is present at these points. The dark grey phase at the boundaries of these spalts (points 3 and 5) consists mainly of tungsten rich spalts (50.63 $\mathrm{Wt} \% \mathrm{~W}$ at point 3 and $47.38 \mathrm{Wt} \% \mathrm{~W}$ at point 4 respectively). The coating region below the oxide scale shows a negligible amount of oxygen which infers that this region remained unoxidised. The dominating presence of $\mathrm{Ni}$ at the point 7 indicates the interdiffusion of nickel from the coating into the substrate.

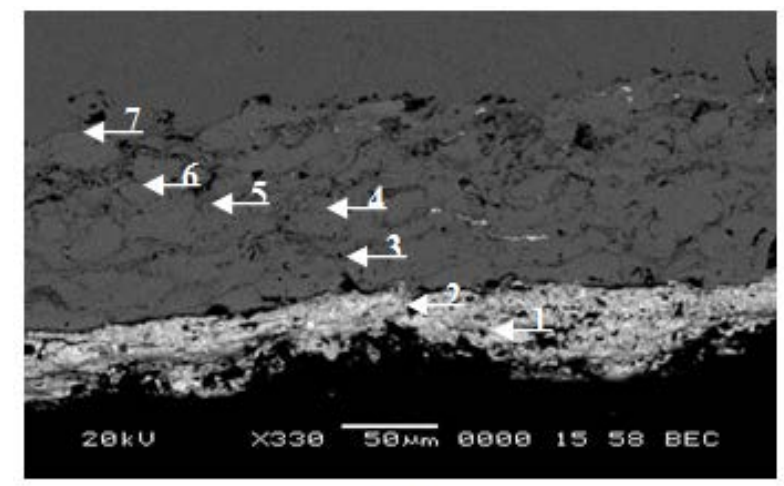

(a)

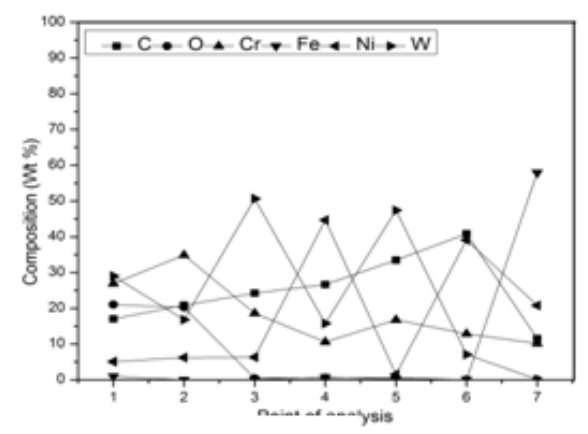

(b)

Figure 8: (a)Back Scattered Electron Image; (b)EDAX Point Analysis (wt \%) Across the Cross-section of the WC-CrC-Ni Coated Steels Subjected to Oxidation

\section{F. EPMA Analysis}

Elemental X-ray mapping for the WC-CrC-Ni coated T22 steel subjected to cyclic oxidation for 50 cycles shows a continuous and adherent thick oxide layer formed on the external surface of the coating as shown in Fig. 9. The coating is oxidized partially which is restricted to few microns on the surface. The $\mathrm{x}$-ray mapping revealed that this adherent top most layer is rich in $\mathrm{Ni}, \mathrm{Cr}$ and $\mathrm{W}$ which corroborates the formation of oxides and spinal oxides of $\mathrm{Ni}$, $\mathrm{Cr}$ and $\mathrm{W}$ on the external surface. Mapping for $\mathrm{W}$ and $\mathrm{C}$ reveals the formation of WC on the external surface of the coating. The absence of $\mathrm{O}$ below the topmost scale reveals that the nickel and tungsten rich spalts are not oxidized at the end of 50 cycles of oxidation studies. The thick oxide scale formed on the surface acts as a 
barrier to the inward diffusion of oxygen and other oxidizing species into the coating.

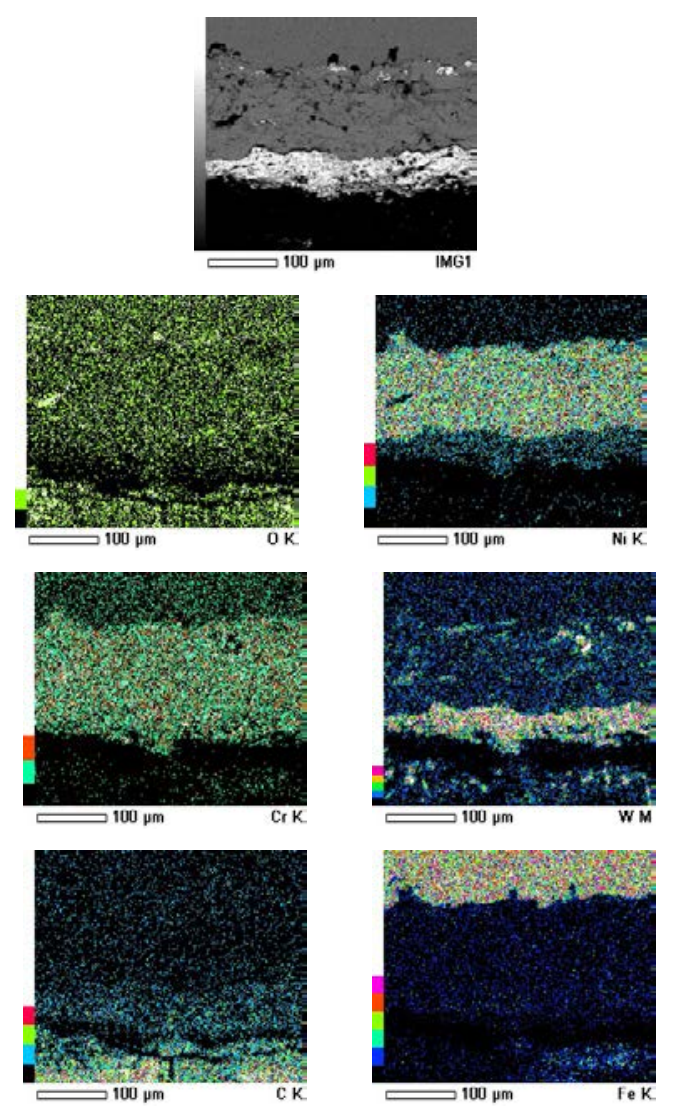

Figure 9: BSEI and Elemental X-ray Mapping at the CrossSection of the WC-CrC-Ni Coated T22 Steels Subjected to Oxidation

\section{Discussion}

The HVOF coatings on the substrate alloys have been successfully deposited and the thickness of the coatings is in the desirable range of 270-300 $\mu \mathrm{m}$. The decreased porosity value of the coatings is linked to the melting behaviour of the powder particles during HVOF spraying and to the higher kinetic energies of powder particles during HVOF spraying. The partially melted particles form an almost porosity-free coating when they reach the substrate at high velocity. The porosity obtained in the sprayed coatings are in good accordance with the findings of Sahraoui et al. [13] for the HVOF sprayed coatings. The coatings showed nearly similar peaks as compared to that of the powder representing no change in their phase composition after HVOF spraying.

The WC-CrC-Ni coated steels show lower weight gain in comparison to the uncoated steels as reported in section III(B). Weight gain after 50 cycles of oxidation of WC-CrC-Ni coated T22, MDN and Superfer steels are found to be 0.79, 0.34 and $0.50 \mathrm{mg} / \mathrm{cm}^{2}$ respectively. The parabolic rate constant $\left(\mathrm{K}_{\mathrm{p}}\right)$ are lower for all the coated steels in comparison to the uncoated steels, thereby further indicating lower oxidation rates for the coated steels. The oxidation behavior of the coated steels is parabolic in nature upto 50 cycles and hence the oxide scales formed have shown the tendency to act as diffusion barriers. The minor deviation from the parabolic rate law can be attributed to the Sputtering of thin oxide layer formed on the surface of the coatings. Hence, it can be inferred that WC-CrC-Ni coatings are successful in protecting the substrate steels from the accelerated oxidation to a considerable extent.

Coatings developed a thick oxide scale after subjecting to 50 cycles of oxidation in air environment. The XRD analysis of the surface of the oxidized scale revealed the existence of $\mathrm{Cr}_{2} \mathrm{O}_{3}, \mathrm{NiO}, \mathrm{WO}_{3}$, WC and mixed spinal-type oxides of $\mathrm{NiWO}_{4}$, and $\mathrm{NiCr}_{2} \mathrm{O}_{4} \cdot \mathrm{Cr}_{3} \mathrm{C}_{2}$ has been predominantly oxidized to form $\mathrm{Cr}$ species. These species are thermodynamically unstable under accelerated oxidation conditions and straight away oxidized to $\mathrm{Cr}_{2} \mathrm{O}_{3}$ [14-16]. The formation of $\mathrm{Cr}_{2} \mathrm{O}_{3}$ and $\mathrm{NiO}$ during the early stages of oxidation lowers the oxygen potential, preventing preferential oxidation of tungsten as $\mathrm{WO}_{\mathrm{x}}$. The refractory tungsten carbide and chromium carbide in the coating retains the properties of the coating by acting as a strengthener. After completion of the $\mathrm{Cr}_{2} \mathrm{O}_{3}$ external scale, the solid state reaction between initially grown stable binary oxides replaces ternary oxides such as $\mathrm{NiWO}_{4}$, and $\mathrm{NiCr}_{2} \mathrm{O}_{4}$ during the intermediate stages of oxidation. The non protective spinel oxide $\mathrm{NiWO}_{4}$ induce formation of a friable and porous scale which was responsible for the increase in oxidation rate. Since $\mathrm{NiWO}_{4}$ is a compound of $\mathrm{NiO}$ and $\mathrm{WO}_{3}, \mathrm{NiWO}_{4}$ would have poor oxidation resistance in the given oxidation environment. Similar observations have been reported by Peters et al. [17] and Lee et al. [18]. The spinel $\mathrm{NiCr}_{2} \mathrm{O}_{4}$, have much smaller diffusion coefficients of the cations and anions than those in their parent oxides, hence helps to develop oxidation resistance [19].

EPMA and EDAX analysis along the cross section of the oxidized coating reveal that oxidation has been restricted only to the external surface upto few microns to form a thick and continuous oxide scale and rest of the coating below the protective oxide layer formed remains unoxidised. Oxygen has not penetrated into the substrate steel, which further indicates that the protective oxides of $\mathrm{Cr}$. Ni and their spinel oxides acts as diffusion barrier to the transportation of oxidizing species into the inside of coating. Hence coating provides necessary protection to the substrate steel.

\section{CONCLUSION}

The following points are concluded based on experimental results:

1. HVOF spray process has been successfully used to deposit WC-CrC-Ni coating on SA213-T22, MDN310 and Superfer $800 \mathrm{H}$ substrates in the range of 270-300 $\mu \mathrm{m}$ thickness. The microhardness and bond strength recorded was $1093 \mathrm{Hv}$ and $73.13 \mathrm{Mpa}$ respectively with porosity less than $2 \%$.

2. The coatings exhibit almost similar peaks as compared to that of the powder indicating no change in their phase composition after spraying. The powder and assprayed coating have major phases of WC, $\mathrm{Cr}_{7} \mathrm{C}_{3}$ and $\mathrm{Cr}_{3} \mathrm{Ni}_{2}$. 
3. The protective oxide scale formed on the outermost surface mainly composed of oxides of $\mathrm{Ni}, \mathrm{Cr}$ and mixed spinel oxide $\mathrm{NiCr}_{2} \mathrm{O}_{4}$. These oxides might have acted as diffusion barrier to the inward diffusion of oxidizing species and hence rest of the coating remains unoxidised. The carbides of tungsten and chromium retain the mechanical properties of the coating.

4. The parabolic rate constant $\left(\mathrm{K}_{\mathrm{p}}\right)$ are lower for all the coated steels in comparison to the uncoated steels and hence the WC-CrC-Ni coating is successful in protecting the substrate steels against the accelerated oxidation.

\section{ACKNOWLEDGMENT}

The authors are very thankful to M/S Metallizing Equipment Co.Pvt.Ltd., Jodhpur, India for having provided coating facility. They also wish to acknowledge National Institute of Technology, Surathkal and Poornaprajna Lab, Bangalore for providing SEM/EDAX and XRD facilities.

\section{REFERENCES}

[1] M.A. Uusitalo, P.M.J. Vuoristo and T.A. Mantyla, "High Temperature Corrosion of Coatings and Boiler Steels in Oxidizing Chlorinecontaining Atmosphere", Materials Science and Engineering. AStructural Materials, vol. 346, Pp. 168-177, 2003.

[2] ASM Handbook, Properties and Selection: Irons, steels and high performance alloys, Vol. 1, ASM Publication, Materials park, Ohio, 2001.

[3] P. Richer, M. Yandouzi, L. Beauvais and B. Jodoin, "Oxidation behaviour of CoNiCrAlY bond coats produced by plasma, HVOF and cold gas dynamic spraying”, vol. 204, No. 24, Pp. 3962-3974, 2010.

[4] J.F. Santa, L.A. Espitia, J.A. Blanco, S.A. Romo and A. Toro, "Slurry and cavitation erosion resistance of thermal spray coatings”, Wear, vol. 267, Pp. 160-167, 2009.

[5] G. Sreedhar, M.D. Masroor Alam and V.S. Raja, "Hot corrosion behaviour of plasma sprayed $\mathrm{YSZ} / \mathrm{Al}_{2} \mathrm{O}_{3}$ dispersed NiCrAlY coatings on Inconel-718 superalloy", Surface and Coatings Technology, vol. 204, No. 3, Pp. 291-299, 2009.

[6] N. Bala, H. Singh and S. Prakash, "Accelerated hot corrosion studies of cold spray Ni-50Cr coating on boiler steels", Materials and Design, vol. 31, No. 1, Pp. 244-253, 2010.

[7] A. Scrivani, S. Ianelli, A. Rossi, R. Groetti, F. Casadei and G. Rizzi, “A contribution to the surface analysis and characterisation of HVOF coatings for petrochemical application”, Wear, vol. 250, Pp.107-113, 2001.

[8] W.M. Zhao, Y. Wang, L.X. Dong, K.Y. Wu and J. Xue, "Corrosion mechanism of NiCrBSi coatings deposited by HVOF", Surface and Coatings Technology, vol. 190, Pp. 293-298, 2005.

[9] S. Thiele, K. Sempf, K.J. Roessler, L.M. Berger and J. Spatzier, "Thermophysical and Microstructural Studies on Thermally Sprayed Tungsten Carbide-Cobalt Coatings", Journal of Thermal Spray Technology, vol. 20, No. 1-2, Pp. 358-365, 2011.

[10] N. Jegadeeswaran, M.R. Ramesh and K. Udaya Bhat, "Hot Corrosion Studies on As-received and HVOF Sprayed Al2O3+CoCrAlTaY on Ti31 Alloy in Salt Environment”, Procedia Engineering, vol. 64, Pp. 1013-1019, 2013.

[11] P. Liam Ward and Antony Pilkington, "The Dry Sliding Wear Behavior of HVOF-Sprayed WC: Metal Composite Coatings", Journal of Materials Engineering and Performance, vol. 23, Pp. 3266- 3278, 2014.

[12] Lutz-Michael Berger, Sabine Saaro, Tobias Naumann, Michaela Kasparova and Frantisek Zahalka, "Microstructure and Properties of HVOF-Sprayed WC-(W,Cr)2C-Ni Coatings”, Journal of Thermal Spray Technology, vol. 17, Pp. 395- 403, 2008.

[13] Sahraoui, Nour-Eddine Fenineche, Ghislain Montavon and Christian Coddet, "Structure and wear behaviour of HVOF sprayed $\mathrm{Cr}_{3} \mathrm{C}_{2}-\mathrm{NiCr}$ and WC-Co coatings", Materials and Design, vol. 24, Pp. 309-313, 2003.
[14] Ching-An Jeng and Jow-Lay Huang, "The influence of oxidation on crack resistance in injection moulded $\mathrm{Cr}_{3} \mathrm{C}_{2} / \mathrm{Al}_{2} \mathrm{O}_{3}$ composites", Journal of the European Ceramic Society, vol. 23, Pp. 1477-1484, 2003.

[15] S. Loubike, Ch. Laurent, J.P. Bonino and A. Rousset, "Elaboration, Microstructure and reactivity of $\mathrm{Cr}_{3} \mathrm{C}_{2}$ powders of different morphology”, Materials Research Bulletin, vol. 30, Pp. 1535-1546, 1995.

[16] D.E. Hajas, M. Baben, B. Hallstedt, R. Iskandar, J. Mayer and J.M. Schneider, "Oxidation of $\mathrm{Cr}_{2} \mathrm{AlC}$ coatings in the temperature range of 1230 to $1410{ }^{\circ} \mathrm{C}$ ”, Surface and Coatings Technology, vol. 206, Pp. 591598, 2011.

[17] K.R. Peters, D.P. Whittle and J. Stringer, "Oxidation and hot corrosion of nickel based alloys containing molybdenum”, Corrosion Science, vol. 16, Pp. 791-804,1976.

[18] D.B. Lee, J.H. Ko and S.C. Kwon, "Oxidation of Ni-W coatings at 700 and $800{ }^{\circ} \mathrm{C}$ in air”, Surface and Coatings Technology, vol. 193, Pp. 292296, 2005.

[19] U.K. Chatterjee, S.K. Bose and S.K. Roy, Environmental Degradation of Metals, Marcel Dekker Publications, New York, 2001.

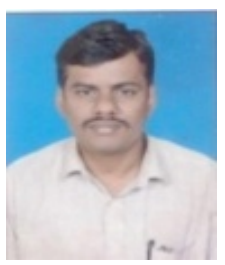

B. Somasundaram received his degree in Mechanical Engineering in 1999 and Masters in Manufacturing Technology from Visveswaraiah Technological University in 2005 and Currently pursuing doctoral programme in Thermal coatings in National Institute of Technology, Karnataka, Surathkal, India. He is working as a Senior Assistant Professor in the Department of Mechanical Engineering, Reva ITM, Bangalore, India. $\mathrm{He}$ is a member of ISTE. He secured First rank in MTech and received gold medal from VTU. Other research interests are Solidification and wear applications.

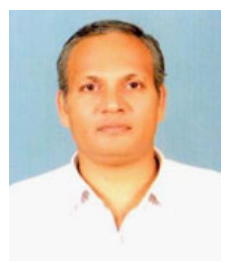

Ravikiran Kadoli received his B.E. degree in Mechanical Engineering in 1989 and Masters in Advanced Manufacturing Engineering in 1993 from NITK Surathkal. He obtained his PhD from IIT Madras in the year 2004. At present, he is a Professor at the National Institute of Technology, Karnataka, Surathkal, India. $\mathrm{He}$ is having a membership to several professional bodies and has more than 10 international publications in peer reviewed journals to his credit. His research areas cover surface coatings, structural mechanics, and applications of advanced materials.



M.R. Ramesh graduated from Bangalore University with a degree in Mechanical Engineering in 1999 and MTech in Manufacturing Science and Engineering from Visveswaraiah Technological University in 2002. He was awarded Doctorate from Indian Institute of Technology, Roorkee in 2008. Presently, he is working as an Assistant Professor in the Department of Mechanical Engineering, National Institute of Technology Karnataka, Surathkal, India. He has authored eight papers in refereed journals and conferences. His research areas cover Thermal Spray Coatings, Advanced Materials Characterization, Bio Fuels, FEA, Wear, Erosion, Oxidation \& Hot Corrosion. 